\title{
Sacrococcygeal cornua as zygapophysial joints
}

\author{
Patrick M. Foye $\cdot$ Milin N. Vora
}

Received: 31 December 2013/ Accepted: 3 January 2014/Published online: 17 January 2014

(C) Japanese Association of Anatomists 2014

Keywords Coccyx $\cdot$ Pain $\cdot$ Coccydynia $\cdot$ Sacrococcygeal joint $\cdot$ Cornu $\cdot$ Nerve block

We applaud your journal and authors Woon and Stringer on the excellent recent article entitled "The anatomy of the sacrococcygeal cornual region and its clinical relevance" (Woon and Stringer 2013). This publication has great clinical relevance for patients with coccydynia (tailbone pain).

Importantly, the authors mentioned the coccygeal cornua articulating with the sacral cornua, corresponding to the way that zygapophysial joints (often referred to as z-joints, or facet joints) are formed at other levels of the vertebral spine. Further discussion of these anatomic correlates is relevant and warranted. For reference and comparison, we note that each lumbosacral z-joint at L5-S1 is formed by the articulation of the inferior articular process of L5 with the ipsilateral superior articular process of S1. Similarly, each corresponding sacrococcygeal zygapophysial joint (at S5-C1) is formed by the sacral cornu (inferior articular process of S5) and the ipsilateral coccygeal cornu (superior articular process of C1). It is logical to expect that somatic innervation patterns at the sacrococcygeal z-joints are similar to those well known throughout the cervical, thoracic, and lumbosacral z-joints. Specifically, innervation is via the medial branch of the dorsal primary rami, which can be targeted for diagnostic and/or therapeutic injections by using the posterolateral approach to place the needle tip at or near the site where the posterior base of the transverse spinous process intersects with lateral base of the superior articular process (Fenton and Czervionke 2003). Understanding how sacrococcygeal z-joints are similar to z-joints at other spinal levels creates a rational anatomic foundation for focal injections at the corresponding sacrococcygeal nerve sites, which is a nonsurgical treatment that is not well known among pain management physicians.

The article and journal are great examples of how the everexpanding details of anatomic knowledge help to expand possible treatment options to relieve human suffering. We would appreciate the authors' additional insights on this.

Conflict of interest None.

\section{References}

Fenton DS, Czervionke LF (2003) Facet denervation. In: Fenton DS, Czervionke LF (eds) Image-guided spine intervention. Saunders, Philadelphia, pp 51-70

Woon JT, Stringer MD (2013) The anatomy of the sacrococcygeal cornual region and its clinical relevance. Anat Sci Int. 2013 Dec 17. [Epub ahead of print] doi:10.1007/s12565-013-0222-x

\footnotetext{
P. M. Foye $(\bowtie) \cdot$ M. N. Vora

Department of Physical Medicine and Rehabilitation,

Coccyx Pain Center, Rutgers New Jersey Medical School,

90 Bergen St, D.O.C. Suite 3100, Newark, NJ 07103-2425,

United States of America

e-mail: doctor.foye@gmail.com; patrick.foye@ rutgers.edu

M. N. Vora

e-mail: Milinvora@gmail.com
} 